УДК 641. 546.45

DOI 10.47049/2226-1893-2021-2-94-104

\title{
УСОВЕРШЕНСТВОВАНИЕ ТЕРМОДИНАМИЧЕСКОГО ЦИКЛА ХОЛОДИЛЬНОЙ УСТАНОВКИ РЕФРИЖЕРАТОРНОГО КОНТЕЙНЕРА ДЛЯ ПЕРЕВОЗКИ И ХРАНЕНИЯ ВАКЦИНЫ NVX-COV2373
}

А.А. Вассерман

доктор технических наук, профессор кафедры «Судовые энергетические установки и техническая эксплуатация»

\section{А.Г. Слынько}

кандидат технических наук, профессор кафедры «Судовые энергетические установки и техническая эксплуатация»

Одесский наииональный морской университет, Украина, Одесса

Аннотация. Предлагается оборудовать рефрижераторные контейнеры для перевозки и хранения вакцины NVX-COV2373 модифичированными холодильными установками. Модификации подвержен термодинамический иикл холодильной установки. Суть модификации состоит в замене адиабатных процессов сжатия рабочих тел во всех изиклах двухкаскадной холодильной установки политропными процессами.

Расчёты показали, что при таком усовершенствовании термодинамического ичика холодильной установки суточная экономия электроэнергии составит на один контейнер около $100 \mathrm{\kappa Bm} \cdot ч а с$, а годовая - более $35 \mathrm{MBm}$ час, что соответствует больше $26 \mathrm{\kappa г/сут.} \mathrm{или}$ около $10 \mathrm{~m} / 2 о д$ дизельного топлива при использовании для получения электроэнергии дизель генератора с удельным расходом топлива $0,270 \kappa 2 / \kappa B m \cdot ч a c$.

Ключевые слова: рефрижераторный контейнер, холодильная установка, усовершенствование термодинамического иикла, адиабатный и политропный процесс, эффективность работы.

УДК 641. 546.45

DOI 10.47049/2226-1893-2021-2-94-104

\section{УДОСКОНАЛЕННЯ ТЕРМОДИНАМІЧНОГО ЦИКЛУ ХОЛОДИЛЬНОЇ УСТАНОВКИ РЕФРИЖЕРАТОРНОГО КОНТЕЙНЕРА ДЛЯ ТРАНСПОРТУВАННЯ ТА ЗБЕРІГАННЯ ВАКЦИНИ NVХ-COV2373}

О.А. Вассерман

доктор технічних наук, професор кафедри

«Суднові енергетичні установки та технічна експлуатація»

$$
\text { О.Г. Слинько }
$$

кандидат технічних наук, професор кафедри

«Суднові енергетичні установки та·технічна експлуатація»

Одеський національний морський університет, Україна, Одеса

(C) Вассерман А.А., Слынько А.Г., 2021 
Анотація. Пропонується рефрижераторні контейнери для транспортування $i$ зберігання вакцини NVX-COV2373 обладнувати холодильними установками з модифікованими термодинамічними циклами. Сенс модифікаиії заключається в заміні адіабатних процесів стиснення робочих тіл в двокаскадній холодильній установиі політропними процесами. Розрахунки показали, що при такому удосконаленню термодинамічного ииклу холодильної установки добова економія електроенергії на один контейнер складе майже $100 \kappa$ квтгоо, а річна - більш ніж 35 МВтггод, що відповідає економії більш ніж 26 кг/добу, або $10 \mathrm{~m} / \mathrm{pi \kappa}$ дизельного палива при використанні для вироблення електричної енергії дизель генератора, питома витрата палива в якому дорівнює $0,270 \kappa г / \kappa B m . г о \partial$

Ключові слова: рефрижераторний контейнер, холодильна установка, удосконалення термодинамічного иџклу, адіабатний і політропний процес стиснення, ефективність роботи.

UDC 641. 546.45

DOI 10.47049/2226-1893-2021-2-94-104

\title{
IMPROVEMENT OF THERMODYNAMIC CYCLE REFRIGERATING INSTALLATION CONTAINER FOR TRANSPORTATION AND STORAGE OF VACCINE NVX-COV2373
}

\author{
A.A. Vasserman \\ Doctor of technical sciences, \\ Professor of department «Ships energetic plants and technical operation» \\ A.G. Slyn'ko \\ Candidate of technical sciences, \\ Professor of department «Ships energetic plants and technical operation»

\section{Odessa National Maritime University, Ukraine, Odessa}

Abstract. Thermodynamic cycles of open gas turbines plants are considered with heat supply to working media processes at constant pressure and volume. As result of theoretical analysis and comparing calculations is established that at different conditions of comparison thermal coefficient of efficiency of cycle with heat supply at constant volume at many cases is greater than КПД of cycle with heat supply at constant pressure.

Keywords: gas turbine plant, heat supply at constant volume and pressure, thermal coefficient of efficiency, specific power.

Введение. Газотурбинные установки (ГТУ) - перспективный тип энергетических установок $[1,2]$. Существенным преимуществом их перед паротурбинными установками является отсутствие котла, так как топливо сжигается в потоке рабочего тела. Газотурбинные уста- 
ВІСНИК

ОДЕСЬКОГО НАЦІОНАЛЬНОГО МОРСЬКОГО УНІВЕРСИТЕТУ № 2 (65), 2021
HERALD

OF THE ODESSA NATIONAL

MARITIME UNIVERSITY № 2 (65), 2021

новки получат всё большее распространение в стационарной энергетике и на транспортных судах по мере повышения их экономичности, экологичности и моторесурса.

В современных открытых ГТУ теплота к рабочему телу подводится в процессе сгорания топлива при постоянном давлении. Встречаются также открытые ГТУ со сгоранием топлива при постоянном объёме, в которых камера сгорания оборудуется управляемыми клапанами. Топливо в камере сгорает при постоянном объёме (при закрытых клапанах), а после конца сгорания открывается выпускной клапан и газы подаются на лопатки турбины. Если на моторесурс влияют конструктивные особенности таких ГТУ, то вопросы экономичности не очевидны.

Целью статьи является выполнение теоретического анализа и сопоставительных расчётов термодинамических циклов ГТУ с изобарным и изохорным подводом теплоты при различных условиях для определения соотношения их основных энергетических характеристик.

Изложение основного материала. На рис. 1 на диаграмме $T, s$ изображены совместно циклы ГТУ с изобарным и изохорным подводом теплоты при одинаковых предельных температурах и степени повышения давления воздуха в компрессоре. При таком сопоставлении циклов видно, что в «изохорном» цикле 1-2-3'-4'-1 и «изобарном» 1-2-3-4-1 средние температуры подвода теплоты одинаковы, а средняя температура отвода теплоты ниже в «изохорном» цикле. Поэтому при указанных условиях термический КПД цикла с изохорным подводом теплоты выше.

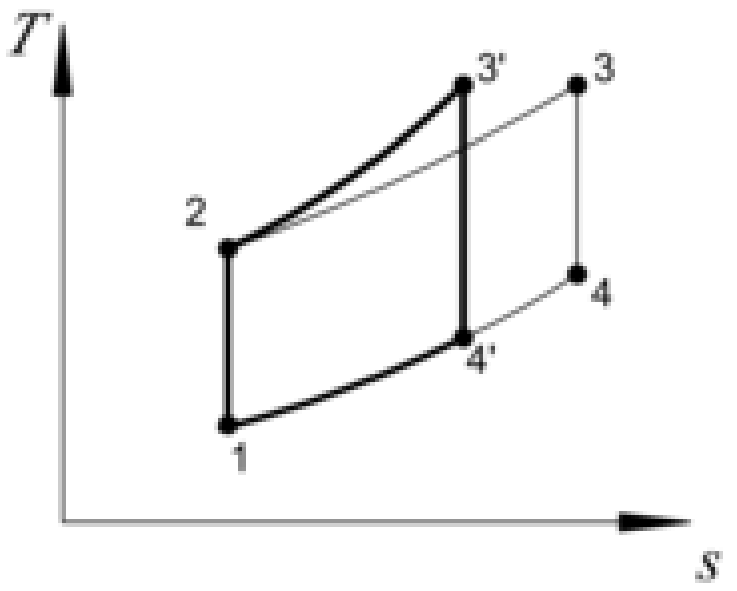

Рис. 1. Сопоставление термодинамических ичиклов ГТУ с изобарным и изохорным подводом теплоты (1-2-3-4-1 и 1-2-3'-4'-1)

при одинаковых $\beta$ и предельных температурах 
ВІСНИК

ОДЕСЬКОГО НАЦІОНАЛЬНОГО МОРСЬКОГО УНІВЕРСИТЕТУ № 2 (65), 2021
HERALD

OF THE ODESSA NATIONAL

MARITIME UNIVERSITY № 2 (65), 2021

Для количественной оценки соотношения термических КПД этих циклов выполнены расчёты при следующих исходных данных: температура и давление атмосферного воздуха $30^{\circ} \mathrm{C}$ и 0,101325 МПа, степень повышения давления воздуха в компрессоре $\beta=7$, температура газов, поступающих на лопатки турбины $-850{ }^{\circ} \mathrm{C}$. Результаты расчётов приведены в табл. 1, из которой видно, что при указанных выше условиях сравнения и исходных данных термический КПД цикла с изохорным подводом теплоты на 15,1% выше КПД цикла с изобарным подводом.

Таблица 1

Сопоставление характеристик ииклов ГТУ с изобарным и изохорным процессами подвода теплоты при одинаковых предельных температурах и степени повышения давления $\beta$

\begin{tabular}{|l|c|c|c|}
\hline \multirow{2}{*}{ Характеристики циклов } & \multirow{2}{*}{$\begin{array}{c}\text { Размер- } \\
\text { ность }\end{array}$} & \multicolumn{2}{|c|}{ Подвод теплоты } \\
\cline { 3 - 5 } & & по изобаре & по изохоре \\
\hline $\begin{array}{l}\text { Температура воздуха после компрес- } \\
\text { сора }\end{array}$ & ${ }^{\circ} \mathrm{C}$ & \multicolumn{2}{|c|}{255,4} \\
\hline $\begin{array}{l}\text { Tемпература газов в начале расшире- } \\
\text { ния }\end{array}$ & ${ }^{\circ} \mathrm{C}$ & \multicolumn{2}{|c|}{850} \\
\hline Давление газов в начале расширения & МПа & 0,7093 & 1,5071 \\
\hline Давление газов в конце расширения & МПа & \multicolumn{2}{|c|}{0,101325} \\
\hline $\begin{array}{l}\text { Температура газов в конце расшире- } \\
\text { ния }\end{array}$ & ${ }^{\circ} \mathrm{C}$ & 371,0 & 246,2 \\
\hline Средняя температура подвода теплоты & ${ }^{\circ} \mathrm{C}$ & \multicolumn{2}{|c|}{515,5} \\
\hline Средняя температура отвода теплоты & ${ }^{\circ} \mathrm{C}$ & 179,3 & 128,5 \\
\hline Количество подводимой теплоты & кДж/кг & 597,5 & 426,8 \\
\hline Количество отводимой теплоты & кДж/кг & 342,6 & 217,2 \\
\hline $\begin{array}{l}\text { Отношение работы компрессора } \\
\text { к работе турбины }\end{array}$ & $\%$ & 47,1 & 37,1 \\
\hline Удельная мощность ГТУ & кВт & 254,8 & 380,2 \\
\hline Повышение удельной мощности ГТУ & $\%$ & - & 49,2 \\
\hline $\begin{array}{l}\text { Отношение удельной мощности ГТУ } \\
\text { к подводимой теплоте }\end{array}$ & \% & 42,7 & 89,1 \\
\hline Термический КПД & $\%$ & 42,65 & 49,09 \\
\hline Повышение термического КПД & $\%$ & - & 15,1 \\
\hline
\end{tabular}


ВІСНИК

ОДЕСЬКОГО НАЦІОНАЛЬНОГО

МОРСЬКОГО УНІВЕРСИТЕТУ

№ 2 (65), 2021
HERALD

OF THE ODESSA NATIONAL

MARITIME UNIVERSITY № 2 (65), 2021

Анализируя табличные данные, можно сделать следующие выводы:

- при равных $\beta$ и предельных температурах цикл ГТУ с изохорным процессом подвода теплоты эффективнее: удельная мощность выше на 49,2 \%, а термический КПД - на $15,1 \%$;

- отношение удельной мощности к подводимой теплоте в цикле с изохорным подводом теплоты в 2 раза выше, чем в цикле с изобарным подводом;

-отношение работы, потребляемой компрессором, к работе турбины в «изохорном» цикле уменьшается на $21 \%$, что соответственно уменьшает основной недостаток ГТУ - сопоставимые значения этих работ.

Возможен вариант сравнения этих циклов при одинаковых начальных параметрах воздуха, равных $\beta$ и одинаковых количествах подводимой теплоты в циклах. Из диаграммы $T, s$ видно (рис. 2), что в этом случае при изохорном подводе теплоты средняя температура её подвода выше, чем при изобарном, а средняя температура отвода ниже, что соответственно сказывается на значениях термических КПД циклов.

Результаты расчёта характеристик циклов для этого варианта их сравнения приведены ниже в табл. 2. При расчётах приняты те же исходные данные для базового цикла, что и ранее. Из таблицы видно, что при принятых условиях сопоставления циклов термический КПД цикла с изохорным подводом теплоты на 19,1\% выше, чем у цикла с изобарным подводом.



Рис. 2. Сопоставление термодинамических ичиклов ГТУ с изобарным и изохорным подводом теплоты (1-2-3-4-1 и 1-2-3'-4'-1) при одинаковых начальных параметрах воздуха, равных $\beta$ и одинаковых количествах подводимой теплоты 
ВІСНИК

ОДЕСЬКОГО НАЦІОНАЛЬНОГО

МОРСЬКОГО УНІВЕРСИТЕТУ

№ 2 (65), 2021
HERALD

OF THE ODESSA NATIONAL

MARITIME UNIVERSITY № 2 (65), 2021

Анализируя данные табл. 2, можно заключить следующее:

- при одинаковых параметрах воздуха, всасываемого компрессором, степени повышения давлении $\beta$ и количествах теплоты, подводимой в сопоставляемых термодинамических циклах, удельная мощность турбины в цикле с изохорным подводом теплоты больше на 112,8\%, а термический КПД - на 19,1\% по сравнению с циклом с изобарным подводом теплоты;

- отношение удельной мощности турбины к подводимой теплоте в «изохорном» цикле выше в 2,1 раза при указанных условиях сопоставления;

- отношение работы, потребляемой компрессором, к работе турбины уменьшается в 1,6 раза, что способствует повышению эффективности цикла ГТУ с изохорным процессом подвода теплоты.

Таблицьа 2

Сравнение характеристик ичклов ГТУ с изобарным и изохорным подводом теплоты при одинаковых начальных параметрах воздуха, равных $\beta$ и одинаковых количествах подводимой теплоты

\begin{tabular}{|c|c|c|c|}
\hline \multirow[t]{2}{*}{ Характеристики циклов } & \multirow{2}{*}{$\begin{array}{l}\text { Размер- } \\
\text { ность }\end{array}$} & \multicolumn{2}{|c|}{ Подвод теплоты } \\
\hline & & \multicolumn{2}{|c|}{ до изобаре по изохоре } \\
\hline Температура воздуха после компрессора & ${ }^{\circ} \mathrm{C}$ & \multicolumn{2}{|c|}{255,4} \\
\hline $\begin{array}{l}\text { Температура газов в начале расшире- } \\
\text { ния }\end{array}$ & ${ }^{\circ} \mathrm{C}$ & 850 & 1087,8 \\
\hline Давление газов в начале расширения & МПа & 0,7093 & 1,0878 \\
\hline Давление газов в в конце расширения & МПа & \multicolumn{2}{|c|}{0,101325} \\
\hline Температура газов в конце расширения & ${ }^{\mathrm{o}} \mathrm{C}$ & 371,0 & 322,6 \\
\hline Средняя температура подвода теплоты & ${ }^{\circ} \mathrm{C}$ & 515,8 & 607,0 \\
\hline Средняя температура отвода теплоты & ${ }^{\mathrm{o}} \mathrm{C}$ & 179,3 & 160,0 \\
\hline Количество подводимой теплоты & кДж/кг & \multicolumn{2}{|c|}{597,5} \\
\hline Количество отводимой теплоты & кДж/кГ & 342,6 & 294,0 \\
\hline $\begin{array}{l}\text { Отношение работы компрессора } \\
\text { к работе турбины }\end{array}$ & $\%$ & 47,1 & 29,5 \\
\hline Удельная мощность ГТУ & $\mathrm{KBT}$ & 254,8 & 542,1 \\
\hline Повышение удельной мощности ГТУ & $\%$ & - & 112,8 \\
\hline $\begin{array}{l}\text { Отношение удельной мощности ГТУ } \\
\text { к подводимой теплоте }\end{array}$ & $\%$ & 42,7 & 90,8 \\
\hline Термический КПД & $\%$ & 42,65 & 50,79 \\
\hline Повышение термического КПД & $\%$ & - & 19,1 \\
\hline
\end{tabular}


На рис. 3 изображены совместно на диаграмме T,s циклы ГТУ с изобарным и изохорным подводом теплоты при одинаковых процессах сжатия воздуха в компрессоре и одинаковых температурах газов в конце расширения в турбине. При сравнении таких циклов видно, что в изохорном цикле 1-2-3'-4-1 средняя температура подвода теплоты в процессе 2-3' выше, а средняя температура отвода теплоты в процессе 4-1 такая же, как в изобарном. Поэтому при указанных условиях, как и в предыдущем варианте сопоставления, термический КПД цикла с изохорным подводом теплоты выше.



Рис. 3. Сопоставление термодинамических ииклов ГТУ с изобарным и изохорным прочессами подвода теплоты (1-2-3-4-1 и 1-2-3'-4-1) при одинаковых $\beta$ и параметрах газов в коние расширения

Для определения значений термического КПД рассматриваемых циклов выполнены расчёты при тех же исходных данных и при условии, что в обоих сопоставляемых циклах одинаковы $\beta$ и параметры газа в конце расширения. Результаты расчётов приведены ниже в табл. 3.

Из анализа табличных данных можно сделать следующие выводы:

- при равных $\beta$ и параметрах газа на выходе из турбины цикл ГТУ с изохорным процессом подвода теплоты более эффективный - удельная мощность выше в 2,5 раза, а термический КПД - на 21,4 \%;

- отношение удельной мощности турбины к подводимой теплоте выше в 2,1 раза при указанных условиях сопоставления;

- отношение работы потребляемой компрессором, к работе турбины уменьшается в 1,8 раза, что соответственно уменьшает основной недостаток ГТУ, что является главной задачей по усовершенствованию циклов ГТУ;

- при изохорном подводе теплоты температура газов, поступающих в турбину, существенно выше, чем при изобарном подводе, что неблагоприятно скажется на моторесурсе ГТУ. 
ВІСНИК

ОДЕСЬКОГО НАЦІОНАЛЬНОГО МОРСЬКОГО УНІВЕРСИТЕТУ № 2 (65), 2021
HERALD

OF THE ODESSA NATIONAL

MARITIME UNIVERSITY № 2 (65), 2021

Таблича 3

Сопоставление характеристик ичиллов ГТУ с изобарным и изохорнымм подводом теплоты при одинаковых начальных параметрах воздуха, равных $\beta$ и одинаковых параметрах газа в коние расширения

\begin{tabular}{|c|c|c|c|}
\hline \multirow{2}{*}{ Характеристики циклов } & \multirow{2}{*}{$\begin{array}{c}\text { Размер- } \\
\text { ность }\end{array}$} & \multicolumn{2}{|c|}{ Подвод теплоты } \\
\hline & & \multicolumn{2}{|c|}{\begin{tabular}{l|l} 
по изобаре по изохоре \\
\end{tabular}} \\
\hline Температура воздуха после компрессора & ${ }^{\circ} \mathrm{C}$ & \multicolumn{2}{|c|}{255,4} \\
\hline Температура газов в начале расширения & ${ }^{\circ} \mathrm{C}$ & 850 & 1087,8 \\
\hline Давление газов в начале расширения & МПа & 0,7093 & 1,0878 \\
\hline Давление газов в в конце расширения & МПа & \multicolumn{2}{|c|}{0,101325} \\
\hline Температура газов в конце расширения & ${ }^{\circ} \mathrm{C}$ & 371,0 & 322,6 \\
\hline Средняя температура подвода теплоты & ${ }^{\circ} \mathrm{C}$ & 515,8 & 607,0 \\
\hline Средняя температура отвода теплоты & ${ }^{\circ} \mathrm{C}$ & 179,3 & 160,0 \\
\hline Количество подводимой теплоты & кДж/кг & \multicolumn{2}{|c|}{597,5} \\
\hline Количество отводимой теплоты & кДж/кг & 342,6 & 294,0 \\
\hline $\begin{array}{l}\text { Отношение работы компрессора } \\
\text { к работе турбины }\end{array}$ & $\%$ & 47,1 & 29,5 \\
\hline Удельная мощность ГТУ & $\mathrm{KBT}$ & 254,8 & 542,1 \\
\hline Повышение удельной мощности ГТУ & $\%$ & - & 112,8 \\
\hline $\begin{array}{l}\text { Отношение удельной мощности ГТУ } \\
\text { к подводимой теплоте }\end{array}$ & $\%$ & 42,7 & 90,8 \\
\hline Термический КПД & $\%$ & 42,65 & 50,79 \\
\hline Повышение термического КПД & $\%$ & - & 19,1 \\
\hline
\end{tabular}

Теперь сравним рассматриваемые циклы при одинаковых начальных параметрах воздуха, всасываемого компрессором, и газа, поступающего в турбину. Из диаграммы T,s видно (рис. 4), что в этом случае при одинаковой средней температуре отвода теплоты средняя температура её изохорного подвода ниже, чем изобарного, что соответственно сказывается на значениях термического КПД.

Результаты сопоставительных расчётов для этого варианта приведены в табл. 4. При расчётах приняты те же исходные данные и условие равенства параметров рабочего тела в предельных состояниях циклов. Из таблицы видно, что при таких условиях термический КПД «изохорного» цикла на 18,4\% ниже, чем цикла с изобарным подводом теплоты, а значение $\beta$ изохорного цикла существенно уменьшилось. 


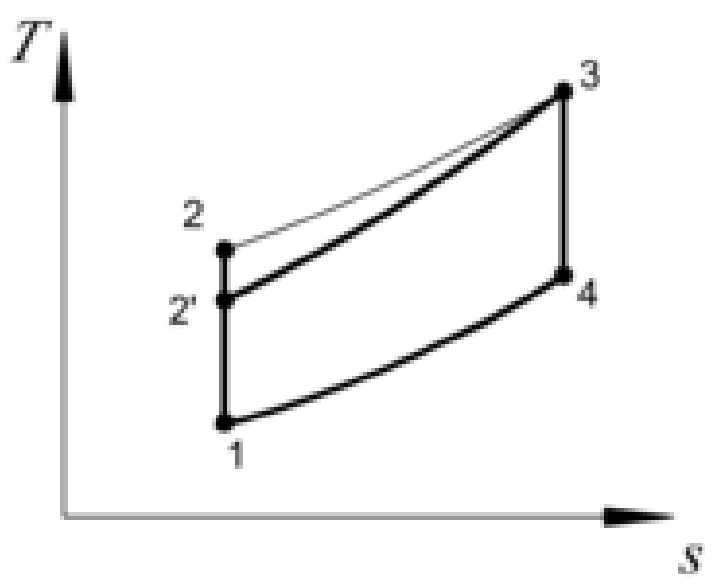

Рис. 4. Сопоставление термодинамических циклов ГТУ

с изобарным и изохорным подводом теплоты (1-2-3-4-1 и 1-2'-3-4-1) при одинаковых предельных состояниях рабочего тела

Из анализа данных табл. 4 можно сделать следующие выводы:

- значение $\beta$ в цикле с изохорным процессом подвода теплоты резко уменьшилось, поэтому уменьшились средняя температура подвода теплоты и термический КПД (на 18,4 \%);

- при равных параметрах рабочего тела в предельных состояниях сопоставляемых циклов удельная мощность турбины в цикле с изохорным подводом теплоты больше на $54,2 \%$, а её отношение к подводимой теплоте больше в 1,75 раза по сравнению с циклом с изобарным подводом теплоты;

- отношение работы, потребляемой компрессором, к работе турбины в «изохорном» цикле меньше в 2,6 раза, что соответственно уменьшает основной недостаток ГТУ - сопоставимость этих работ;

Выводы. Теоретический анализ и расчёты показали, что термический КПД цикла ГТУ с изохорным подводом теплоты выше КПД цикла с её изобарным подводом как при одинаковых предельных температурах циклов, так и при одинаковых количествах подводимой теплоты, а также при одинаковых процессах сжатия воздуха и одинаковых температурах газов в конце расширения. Отношение работы, потребляемой компрессором, к работе турбины в ГТУ с изохорным подводом теплоты меньше, чем в ГТУ с изобарным подводом, что является положительным фактором. 
Сопоставление характеристик изиклов ГТУ с изобарным и изохорным процессами подвода теплоты при одинаковых предельных состояниях рабочего тела

\begin{tabular}{|c|c|c|c|}
\hline \multirow[t]{2}{*}{ Характеристики циклов } & \multirow{2}{*}{$\begin{array}{c}\text { Размер- } \\
\text { ность }\end{array}$} & \multicolumn{2}{|c|}{ Подвод теплоты } \\
\hline & & по изобаре & по изохоре \\
\hline Степень повышения давления воздуха & & 7,0 & 2,437 \\
\hline $\begin{array}{l}\text { Температура воздуха после компрес- } \\
\text { сора }\end{array}$ & ${ }^{\circ} \mathrm{C}$ & 255,4 & 117,9 \\
\hline Температура газов в начале расширения & ${ }^{\circ} \mathrm{C}$ & \multicolumn{2}{|c|}{850} \\
\hline Давление газов в начале расширения & МПа & \multicolumn{2}{|c|}{0,7093} \\
\hline Давление газов в в конце расширения & МПа & \multicolumn{2}{|c|}{0,101325} \\
\hline Температура газов в конце расширения & ${ }^{\circ} \mathrm{C}$ & \multicolumn{2}{|c|}{371,0} \\
\hline Средняя температура подвода теплоты & ${ }^{\circ} \mathrm{C}$ & 515,8 & 420,8 \\
\hline Средняя температура отвода теплоты & ${ }^{\circ} \mathrm{C}$ & \multicolumn{2}{|c|}{179,3} \\
\hline Количество подводимой теплоты & кДж/кг & 597,5 & 525,5 \\
\hline Количество отводимой теплоты & кДж/кг & \multicolumn{2}{|c|}{342,6} \\
\hline $\begin{array}{l}\text { Отношение работы компрессора } \\
\text { к работе турбины }\end{array}$ & $\%$ & 47,1 & 18,3 \\
\hline Удельная мощность ГТУ & кBт & 254,8 & 393,0 \\
\hline Повышение удельной мощности ГТУ & $\%$ & - & 54,2 \\
\hline $\begin{array}{l}\text { Отношение удельной мощности ГТУ } \\
\text { к подводимой теплоте }\end{array}$ & $\%$ & 42,7 & 74,8 \\
\hline Термический КПД & $\%$ & 42,65 & 34,80 \\
\hline Понижение термического КПД & $\%$ & - & $-18,4$ \\
\hline
\end{tabular}

ГТУ с изохорным подводом теплоты конструктивно сложнее по сравнению с ГТУ с изобарным подводом. Тем не менее, для использования в стационарных условиях при большой мощности с экономической и экологической точек зрения они предпочтительнее. 


\begin{tabular}{c|c} 
ВІСНИК & HERALD \\
\hline ОДЕСЬКОГО НАЦІОНАЛЬНОГО & OF THE ODESSA NATIONAL \\
МОРСЬКОГО УНIВЕРСИТЕТУ & MARITIME UNIVERSITY \\
№ 2 (65), 2021 & № 2 (65), 2021 \\
\hline \hline
\end{tabular}

\section{ЛІТЕРАТУРА}

1. Артемов Г.А., Горбов В.М., Романовский Г.Ф. Судовые установки с газотурбинными двигателями. - Николаев: УГМТУ, 1997. - $233 c$.

2. Вассерман О.А., Слинько О.Г., Шутенко М.А. Інновачійні термодинамічні иикли енергетичних установок. - Одеса, Фенікс, 2020. - 184 c.

\section{REFERENCES}

1. Artemov, G.A., Gorbov, V.M. and Romanovskiy, G.F. (1997). Sudovye ustanovki s gazoturbinnymi dvigatelyami. - Nikolaev: UGMTU. -233 p. (Ship `s plants with gas turbines engines.

2. Vasserman, A.A., Slyn ko, A.G. and Shutenko, M.A. (2020) Innovatsiyni termodinamichni tsikly energeticheskikh ustanovok. Odessa: Feniks. - 184 p. (Innovatory thermodynamic cycles of energetic plants).

Стаття надійшла до редакиії 08.02.2021

Посилання на статтю: Вассерман А.А., Слынько. Усовершенствование термодинамического цикла холодильной установки рефрижераторного контейнера для перевозки и хранения вакцины NVX-COV2373 // Вісник Одеського національного морського університету: Зб. наук. праць, 2021. № 2(65). С. 94-104. DOI 10.47049/ 2226-1893-2021-2-94-104.

Article received 08.02.2021

Reference a JournalArtic: Vasserman A.A., Slyn 'ko A.G. Improvement of thermodynamic cycle refrigerating installation container for transportation and storage of vaccine NVX-COV2373 // Herald of the Odessa national maritime university. 2021. № 2(65). 94-104. DOI 10.47049/ 2226-1893-2021-2-94-104. 